\title{
Respiratory inhibition of isolated mammalian mitochondria by salivary antifungal peptide histatin-5
}

\author{
R. Petruzzelli, ${ }^{\mathrm{a}, *}$ M.E. Clementi, ${ }^{\mathrm{b}}$ S. Marini, ${ }^{\mathrm{c}}$ M. Coletta, ${ }^{\mathrm{c}}$ E. Di Stasio, ${ }^{\mathrm{b}}$ \\ B. Giardina, ${ }^{b}$ and F. Misiti ${ }^{\text {b }}$ \\ a Department of Biomedical Sciences, University "G. D'Annunzio" Via dei Vestini, 31, 66100 Chieti Scalo (CH), Italy \\ ${ }^{\mathrm{b}}$ Institute of Biochemistry and Clinical Biochemistry and CNR Institute "Chimica del Riconoscimento Molecolare," Faculty of Medicine, \\ Catholic University, Largo F. Vito 1, 00168 Rome, Italy \\ ${ }^{\mathrm{c}}$ Department of Experimental Medicine and Biochemical Sciences, University of Rome Tor Vergata, Via di Tor Vergata, 135-00133 Rome, Italy
}

Received 7 October 2003

\begin{abstract}
Histatin-5 is a peptide secreted in the human saliva, which possesses powerful antifungal activity. Previous studies have shown that this peptide exerts its candidacidal activity, through the inhibition of both mitochondrial respiration and the formation of reactive oxygen species. The purpose of the present study was to investigate the biological consequences of histatin-5 action on mammalian mitochondria to verify if the toxic mechanism exerted on mitochondria from Candida albicans is an exclusive for fungal cells. Moreover, hypothesising that the damage exerted on mitochondria may induce programmed cellular death pathways, we evaluated two main markers of apoptosis: the mitochondrial membrane potential $(\Delta \Psi)$ and the release of cytochrome $c$. The results obtained show that exposure of isolated mammalian mitochondria to histatin-5 determines: (i) a large inhibition of the respiratory chain at the level of complex I, (ii) a slight decrease in the mitochondrial membrane potential, and (iii) no release of cytochrome $c$. (c) 2003 Elsevier Inc. All rights reserved.
\end{abstract}

Keywords: Histatin-5; Salivary peptides; Mitochondria; Apoptosis

Histatins (Hsts) are a family of related cationic histidine-rich polypeptides of variable length found in abundance in the saliva of humans and old-world monkeys [1,2]. The primary structure of the major family members (Hist-1, -3 , and -5 ) has been determined and indicates that these peptides consist of 38,32 , and 24 amino acids, respectively [3,4]. Many of the smaller members of the histatin family are proteolytic products of Hist-1 and Hist-3. Histatins demonstrate a number of biological activities in vitro, including maintenance of tooth surface integrity, the induction of histamine release, and inhibition of proteases [5-9]. Histatins have potential as therapeutic agents against oral candidiasis [10], being potent antifungal molecules with a low toxicity to human cells, as evidenced by its lack of lytic activity to human erythrocytes and various human cell

\footnotetext{
${ }^{*}$ Corresponding author. Fax: +39-0871-355-5356.

E-mail address: r.petruzzelli@dsb.unich.it (R. Petruzzelli).
}

lines and primary cells $[11,12]$. In vitro studies demonstrate that histatin-5 is the most potent candidacidal member of the family, killing pathogenic Candida species from $90 \%$ to $100 \%$ at physiological concentrations [3]. Biochemical and physiological data evidence that histatin-5 causes structural changes in the cell wall, membrane [13] and it induces release of potassium and ATP $[14,15]$. Earlier reports have suggested that the cytotoxic activity of histatin-5 may be related to the structural features of the C-terminal fragment of the entire peptide, which in a hydrophobic environment has the propensity to assume a non-amphipathic $\alpha$-helical structure [16]. Although several biochemical studies have described the toxicity of this peptide in Candida albicans cells, the real mechanism underlying the toxicity has not yet been established. It has been proposed that a requirement for the cytotoxic activity of the histatin- 5 is an active metabolism of the target cell, as revealed by the protective efficacy of mitochondrial inhibitors or 
anaerobic conditions [17]. Recently, Helmerhorst et al. have demonstrated that histatin-5 after its internalisation within the yeast cell reaches the mitochondria, dissipating the mitochondrial membrane potential $(\Delta \Psi)$. Mitochondria thus seem to represent the main target for histatin within the yeast cell $[18,19]$ and in particular Helemehorst et al. have recently reported that histatin-5 is able to induce the formation of reactive oxygen species (ROS) in C. albicans cells as well as in isolated mitochondria suggesting that this is the ultimate and essential step for the histatin-5-provoked yeast cell death.

This property can be probably related to the metallopeptide nature of histatin-5. In fact Melino et al. [20] have demonstrated that the peptide in the presence of zinc ions is able to aggregate and fuse negatively charged unilamellar vesicles and subsequently it has been reported that histatin-5 binds copper and nickel through its N-terminal ATCUN motif [21].

All these effects are selective for the yeast cells due to the presence of a specific histatin-5 membrane bound receptor [22], recently isolated and characterised as Ssa1/ 2 proteins [23].

With the aim to discriminate intracellular toxic events from the preceding histatin binding and internalisation events, in this study, isolated mammalian mitochondria were used, as system model, to study the biochemical effects of the interaction of histatin-5 with mitochondria. This feature may assume a further interest, in consideration of the fact that in mammalian cells, as well as in unicellular organisms, mitochondria play a crucial role in the regulation and execution of cell death pathways [24-30]. Critical events in apoptosis are the permeabilisation/disruption of their outer membrane, with (or followed by) the loss of mitochondrial transmembrane potential, leading to the release of cytochrome $c$ and other death cell factors [31].

\section{Materials and methods}

Peptide synthesis. Synthetic histatin-5 (DSHAKRHHGYKRK FHRKHHSHRGY) was purchased from Epytop (France). Analysis of the peptide by reverse phase high performance chromatography (HPLC) and mass spectrometry revealed a purity $>98 \%$.

Mitochondrial preparation. The mitochondrial fraction was purified from the hearts of Sprague-Dawley rats according to the method reported in the literature [32]. The right and left ventricles were homogenised in ice-cold homogenisation buffer composed of $280 \mathrm{mM}$ sucrose, $1 \mathrm{mM}$ EDTA, and $10 \mathrm{mM}$ Hepes at $\mathrm{pH}$ 7.2. The homogenate was centrifuged at $1000 \mathrm{~g}$ for $5 \mathrm{~min}$ to remove cell debris. The resulting supernatant was centrifuged at $10,000 \mathrm{~g}$ for $15 \mathrm{~min}$ to isolate the mitochondrial pellet. This washing procedure was repeated twice and the final pellet was resuspended in homogenisation pellet. Protein concentrations were determined by using the Bradford assay kit from Bio-Rad.

Detection of cytochrome $c$ release. Freshly isolated mitochondria were incubated at $25^{\circ} \mathrm{C}$ for $15 \mathrm{~min}$ in the presence of histatin $100 \mu \mathrm{M}$. After the incubation, mitochondria were spun at $15,000 \mathrm{~g}$ for $5 \mathrm{~min}$ at $4{ }^{\circ} \mathrm{C}$ and the resulting supernatants were used for the detection of the cytochrome $c$ by Western blotting analysis. Supernatant proteins were separated by $14 \%$ SDS-PAGE, blotted onto a nitrocellulose membrane, probed by the anticyto c mAb (7H8.2C12, PharMingen), and developed by an amplified detection method (Bio-Rad).

Mitochondrial transmembrane potential. The potential was measured in a fluorometer in the presence of Rhodamine 123 (excitation $490 \mathrm{~nm} / \mathrm{emission} 530 \mathrm{~nm}$ ) [33]. Fluorescence measurements were conducted at either 25 or $37^{\circ} \mathrm{C}$ in $280 \mathrm{mM}$ sucrose, $10 \mathrm{mM}$ Hepes, $1 \mathrm{mM}$ EDTA, $7 \mathrm{mM} \mathrm{MgCl}_{2}, 10 \mathrm{mM} \mathrm{KCl}$, and $0.1 \mu \mathrm{M}$ Rhodamine 123 , pH 7.2 , and adding mitochondrial suspension previously incubated with compounds under analysis at a final concentration of $1 \mathrm{mg} / \mathrm{ml}$. The concentration of histatin was $100 \mu \mathrm{M}$ and the peptide was incubated with mitochondria for $30 \mathrm{~min}$ at $37^{\circ} \mathrm{C}$.

Analysis of mitochondrial functions. For studying mitochondrial functions, $1 \mathrm{mg}$ of mitochondrial protein $/ \mathrm{ml}$ was incubated in $280 \mathrm{mM}$ sucrose, $10 \mathrm{mM}$ Hepes, $5 \mathrm{mM} \mathrm{KH}_{2} \mathrm{PO}_{4}$, and $1 \mathrm{mM}$ EDTA, pH 7.4, in the presence of histatin $100 \mu \mathrm{M}$ and the results were compared with those of not-treated mitochondria. Respiration rates were measured using substrates that enter the electron transport chain selectively at the following specific complexes: for complex I, glutamate $(1.7 \mathrm{mM})$ and malate $(1.7 \mathrm{mM})$; for complex II, succinate $(2.5 \mathrm{mM})$ with NADH dehydrogenase inhibitor $(2 \mu \mathrm{M}$ rotenone). Oxygen consumption was measured at $37^{\circ} \mathrm{C}$ with a Clark-type oxygen electrode (Strathkelvin Instr., Glasgow) under continuous stirring.

Measurement of caspase activity. Recombinant human caspase (Sigma) was incubated with the peptide at $100 \mu \mathrm{M}$, in the presence of DEVD-pNA for $3 \mathrm{~h}$ at $37^{\circ} \mathrm{C}$. Additional control assays with the presence of specific caspase 3 inhibitor (DEVD-CHO) and in the absence of recombinant human caspase were performed for measuring the non-specific hydrolysis of the substrate (data not shown). Substrate cleavage was followed spectrophotometrically at $405 \mathrm{~nm}$.

Fluorescent phase contrast inverted microscope measurements. Human myelomonocytic cells (U-937) were maintained in RPMI 1640 supplemented with 5\% FCS (foetal calf serum), 0,1\% L-glutamine, and $1 \%$ penicillin. Cells were grown in Nunc clone plastic bottles (TedNunc, Roskilde, Denmark) and split twice weekly at cell densities according to standard procedures. The day before splitting cells $(100 \%$ viability as assessed by staining with $1 \%$ trypan blue) were washed twice in RPMI 1640 and suspended at 100,000 cells/ml. Fluorescent compound, at a final concentration of $100 \mu \mathrm{M}$, was added to cell suspensions kept in ice. Incubation was performed for $2 \mathrm{~h}$ at +4 and $+37^{\circ} \mathrm{C}$. Thereafter cells were washed three times with saline solution $(\mathrm{NaCl} 0.7 \%)$ and observed at a fluorescent phase contrast inverted microscope (Olympus IX-70 System). Images were taken by using a $40 \times$ objective. Processing images was done on a PC using the software package Photoshop (Adobe Systems, Mountain View, CA, USA).

Statistics. All of the data were expressed as means $\pm \mathrm{SE}$ of five to seven independent experiments. The significance of differences between control and experimental groups were performed using a two-tailed Student's $t$ test.

\section{Results}

First of all, it is important to provide evidence that our experiments performed on $\mathrm{T}$ human lymphocytes in the presence of FITC-labelled histatin-5 have demonstrated the incapacity of these cells to internalise the peptide (Figs. 1A and B). This result confirms that the salivary peptide is non-toxic for mammalian cells due to the absence on their membrane of the specific binding protein, recently characterised on the cell envelope of C. albicans [23].

In order to assess whether histatin-5 induces changes in the rat mitochondrial functionality, the respiratory 

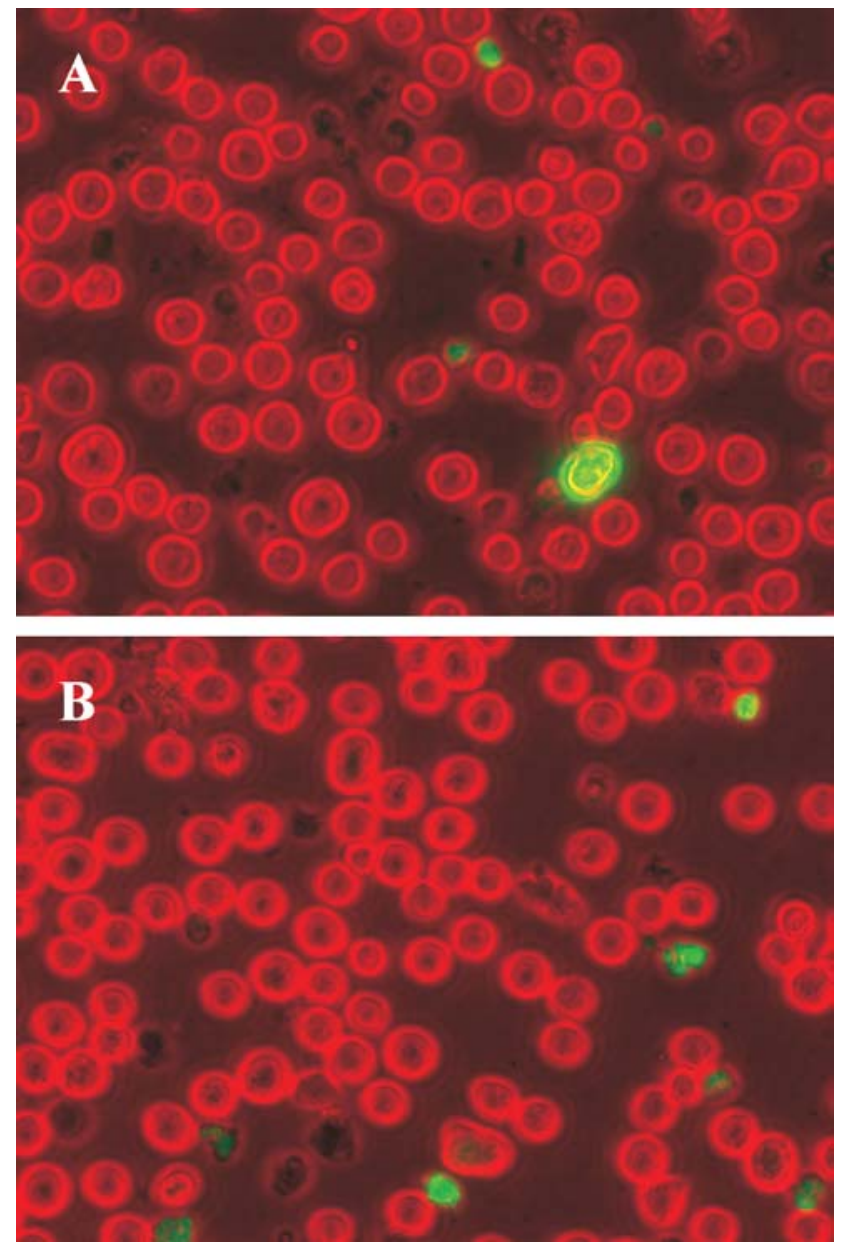

Fig. 1. Confocal fluorescence microscopy images of human mielomonocitic (U-937) cells labelled with FITC-histatin-5. Cells were incubated for $2 \mathrm{~h}$ at $4{ }^{\circ} \mathrm{C}(\mathrm{A})$ and $37^{\circ} \mathrm{C}(\mathrm{B})$.

activity, and the transmembrane potential $(\Delta \Psi)$ have been estimated in the peptide-treated isolated mitochondria. In Fig. 2, the respiratory activity of the mitochondria is shown in the presence of different substrates: succinate and glutamate plus malate that investigate, respectively, the complexes II and I. Histatin-5 was added to mitochondrial suspension in respiratory state 2 . It is interesting to note that the peptide at a concentration of $100 \mu \mathrm{M}$ inhibits mitochondrial respiration only in the presence of glutamate-malate as substrates, implying that inhibition of respiration was occurring probably at the level of the complex I of the respiratory chain. It should be noted that, although the concentration of histatin-5 used in these experiments would not be achievable under physiological conditions, in earlier in vitro studies concerning the toxic effects of histatin-5 on cells, this peptide was used in similar concentration [11,17,19,22].

Mitochondrial membrane potential variations $(\Delta \Psi)$ were followed as fluorescence changes of mitochondrial suspensions in the presence of Rhodamine 123, a fluorescent probe with membrane potential-dependent distributional properties. The addition of succinate or glutamate plus malate to mitochondrial suspensions causes quenching of the probe fluorescence, due to Rhodamine 123 uptake by mitochondria. As shown in Fig. 3, in histatin-5-treated mitochondria, the uptake-rate of the probe fluorescence was lower than that observed in control mitochondria, indicating that, under our experimental conditions, histatin- 5 treatment induces a slight decrease of the mitochondrial membrane potential $(\Delta \Psi)$. It should be noted that this phenomenon was evident exclusively in the experiments performed in the presence of malate and glutamate as substrates (see Fig. 3A).

The next question we addressed was whether any of these functional mitochondrial alterations induced by histatin-5 was associated with the release in the cytosol of cytochrome $c$, a critical event in the apoptotic pathways.

In order to assess cytochrome $c$ release, isolated mitochondria $(1 \mathrm{mg} / \mathrm{ml}$ of proteins) were incubated with $100 \mu \mathrm{M}$ histatin at $37^{\circ} \mathrm{C}$ for $30 \mathrm{~min}$. Supernatants were collected and subjected to immunoblotting analysis.

Fig. 4 shows that a small amount of cytochrome $c$ released was present both in treated and untreated

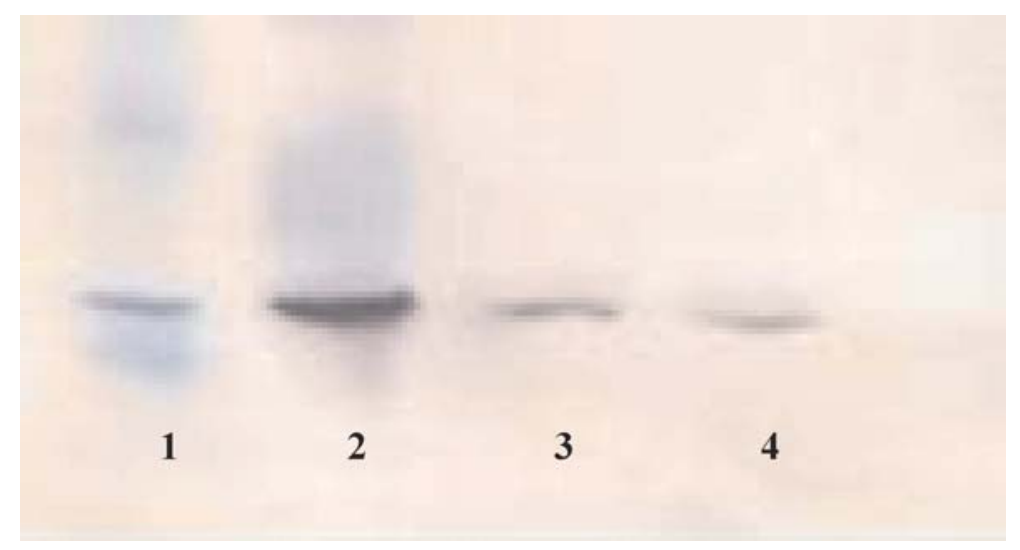

Fig. 4. Representative Western blotting of cytochrome $c$ release from heart mitochondria in the absence (lane 3 ) and in the presence of $100 \mu \mathrm{M}$ histatin-5 (lane 4). Lanes 1 and 2 report the pre-stained molecular weight standard and purified cytochrome $c$ used as control, respectively. 


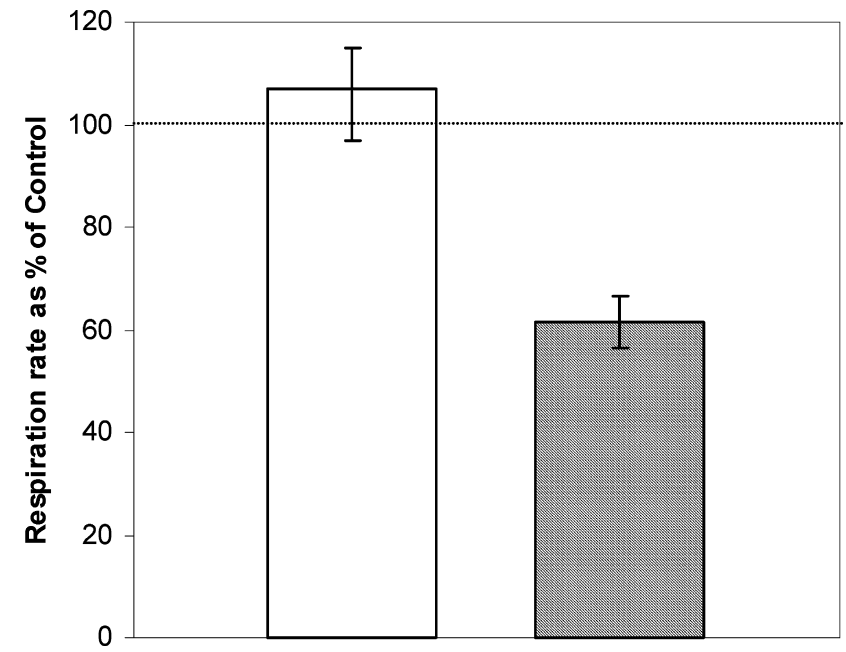

Fig. 2. Effect of $100 \mu \mathrm{M}$ histatin-5 on mitochondrial respiration activity expressed as percentage of control (dotted line $=100 \%$ ) in the presence of succinate (white bars) and glutamate-malate (dotted line bars). Experimental conditions are reported in Materials and methods. Absolute value of oxygen consumption in the absence of peptide was $10.4 \pm 1.2 \mathrm{nmol} / \mathrm{min} / \mathrm{mg}$ protein $(N=12)$ with glutamate-malate as substrate and $12.68 \pm 1.5 \mathrm{nmol} / \mathrm{min} / \mathrm{mg}$ protein $(N=10)$ in the presence of succinate as substrate plus $2 \mu \mathrm{M}$ rotenone. Values presented are means $\pm \mathrm{SE}$ obtained for seven experiments. The statistical significance of the drug treatments was determined by a paired Student's $t$ test $\left({ }^{*} P<0.05\right.$ and ${ }^{* *} P<0.01$ vs. control).

mitochondria. Because no significant differences were observed in both of them, the observed release of cytochrome $c$ in treated mitochondria is probably to associate with the experimental procedures used in the assay, indicating that mitochondrial dysfunction occurring in isolated mammalian mitochondria, following histatin-5 exposure, is not accompanied by any release of cytochrome $c$.

Subsequently, in order to better understand the role of the apoptotic pathways in the mechanism of histatin5 toxicity we investigated the interaction of histatin-5 on the activity of recombinant caspase 3 (see Fig. 5), another critical enzyme involved in the apoptotic pathways [34,35]. Protease activity which resulted inhibited when exposed to histatin-5 $(100 \mu \mathrm{M})$, consistent with a recent paper of Gusman et al. [36], which demonstrates that histatin-5 is a potent competitive inhibitor of cysteine proteinase clostripain.

\section{Discussion}

The present work clearly evidences for the first time that histatin-5 induces changes of the mitochondrial functions in isolated mammalian mitochondria, inhibiting the respiratory activity and dissipating slightly the transmembrane potential $(\Delta \Psi)$.

Our data regarding the respiratory activity of histatin-treated isolated mammalian mitochondria are in
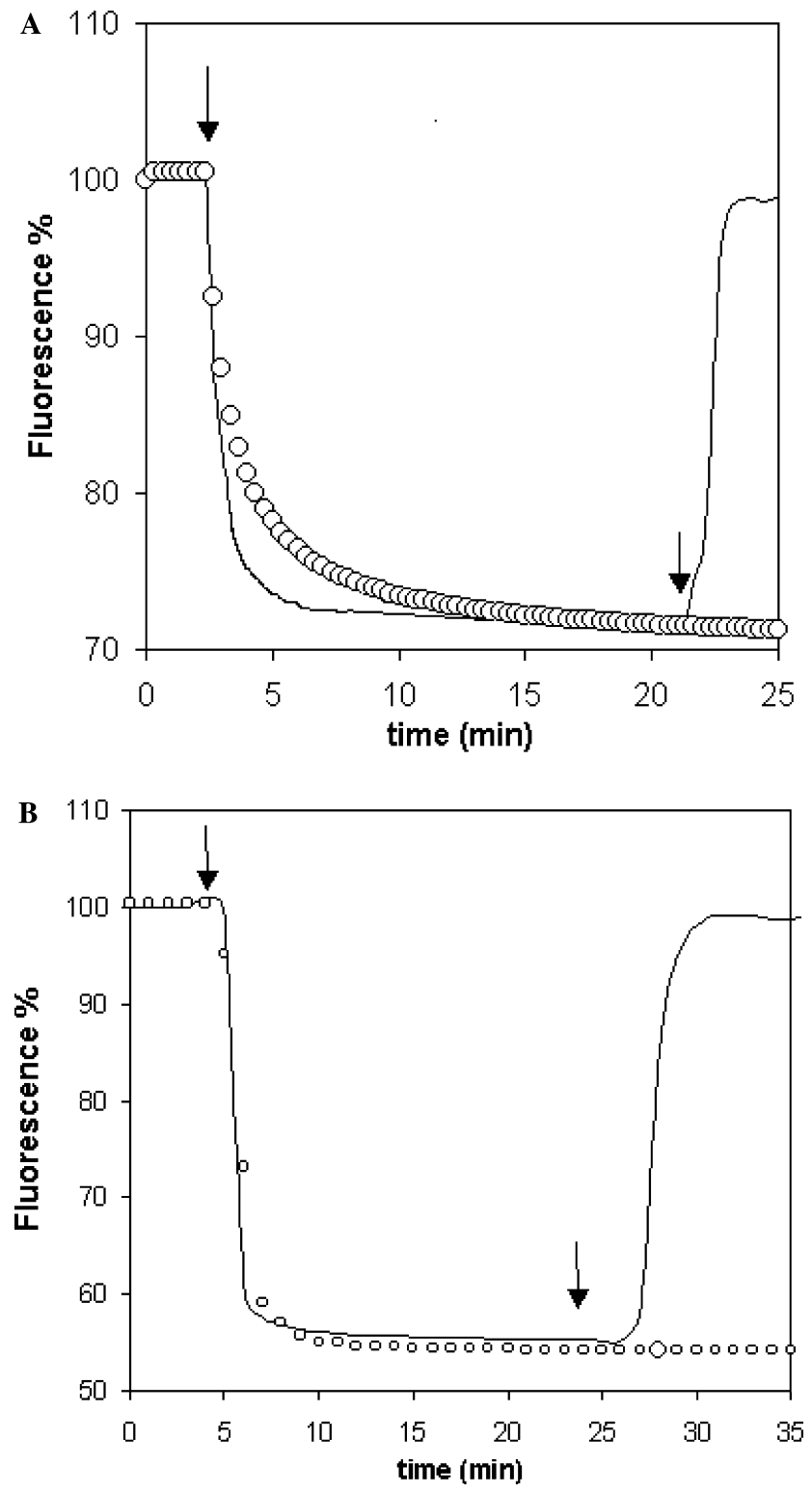

Fig. 3. Mitochondrial energisation monitored by fluorescence quenching of Rhodamine 123 in the in absence (continuous line) and in the presence of $100 \mu \mathrm{M}$ histatin-5 $(\bigcirc)$. The experiments were performed in the presence of glutamate-malate (A) and succinate (B) as substrates. Fluorescence was measured as described in Materials and methods. Where indicated (first arrow) substrate was added; second arrow shows addiction of FCCP to control experiment. The experiments shown are representative for five separate measurements.

agreement with previous studies that reported a dosedependent inhibition of the respiratory activity and a large dissipation of the mitochondrial membrane potential $(\Delta \Psi)$ in $C$. albicans cells, following histatin 5 exposure [17,19]. First, Helmerhorst et al. suggested that histatin-5, after its entrance in the yeast cell, reaches the mitochondria and inhibits the complexes I and/or III of the respiratory chain. However, the amplitude of the dissipation of the transmembrane potential $(\Delta \Psi)$ is quite different in mammalian and in $C$. albicans mitochondria, probably due to differences in the method of membrane 


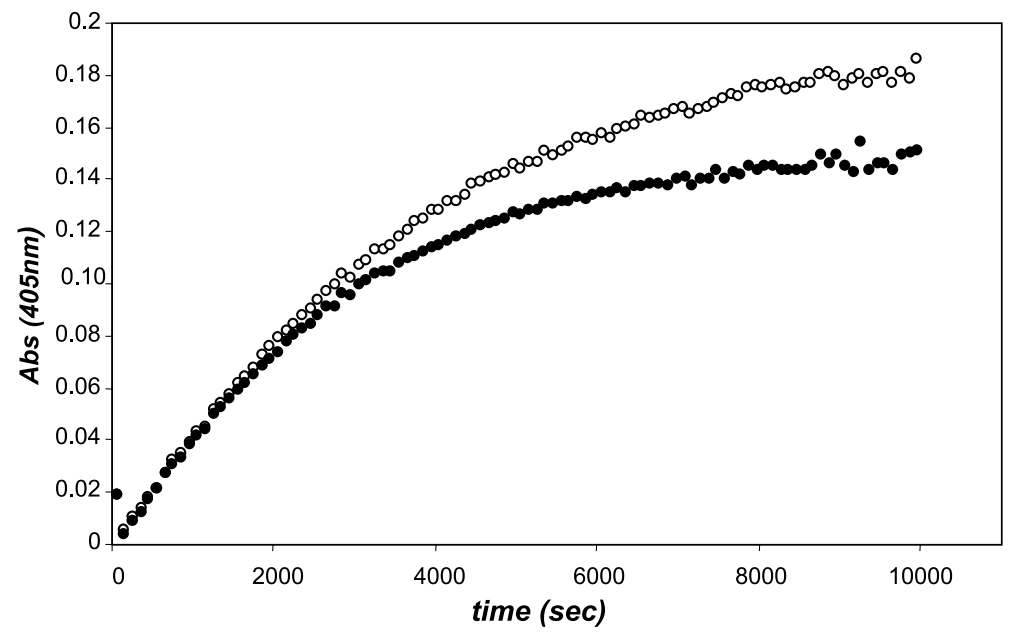

Fig. 5. Activity of caspase 3 (followed as DEVD-pNA cleavage and expressed as optical absorbance at $405 \mathrm{~nm}$ ) in the absence (open symbols) and in the presence of $100 \mu \mathrm{M}$ histatin-5 (closed symbols). The experiment shown is typical for seven separate assays.

potential measurements, and even to the features of the cardiac mitochondria system $[16,17]$.

It is widely accepted that reduction of $\Delta \Psi$ is linked with the release of inter-membrane proteins such cytochrome $c$ [24-26]. Although our results show a slight but significant reduction of $\Delta \Psi$, no significant cytochrome $c$ release was observed under our experimental conditions, in isolated mammalian mitochondria following histatin5 exposure. Whether dissipation of the transmembrane potential $(\Delta \Psi)$ is a primary effect of histatin-5 on the mitochondria or a consequence of cytochrome $c$ release needs probably further work, although our data favour the first possibility. Helmerhorst et al. suggested that a large accumulation of unstable reactive species within the mitochondria of yeast cells after treatment with histatin-5 might likely represent an inevitable consequence of impairment of the mitochondrial respiratory enzymes induced by histatin-5 [19]. Similarly, we suggest that a slight membrane damage induced by the oxygen reactive species generated within the mammalian mitochondria as a consequence of the histatin-5-dependent inhibition of the complex I of the respiratory chain might account for the slight dissipation of the transmembrane potential $(\Delta \Psi)$, we observed, under our experimental conditions, in isolated mammalian mitochondria subsequent to histatin-5 exposure. Thus, although the amplitude of the toxic effects exerted by histatin-5 on mammalian mitochondria was lesser than that reported for $C$. albicans cells, our results suggest that production of ROS may be a metabolic event shared by yeast and mammalian mitochondria. Similarly, it should be noted that the ability of histatin-5 to inhibit human caspase 3 activity might represent an important biological property of this antimicrobial peptide even in C. albicans, in consideration of the existence of a caspase-related protease that regulates apoptosis in yeast [37].
In summary, our results indicate that not only mitochondria from C. albicans [16,17], but also mammalian mitochondria may be targets of histatin- 5 toxic action. This finding supports the hypothesis that binding of histatin-5 to fungal cell membrane and its internalisation and transport represent critical events in the entire killing process $[38,39]$ mediated by histatin-5.

The weak amphipathic character of the $\alpha$-helical structure that the peptide assumes in a hydrophobic environment and the presence of a net positive charge at physiological conditions [40] make improbable a mechanism of internalisation related to the permeabilisation of the biological membranes. In fact, very recently Li et al. [23] provide evidence for a novel function of yeast Ssa1/2 proteins as cell envelope for histatin-5 that mediate fungicidal activity.

Consistent with the existence of specific surface receptors on yeast membrane, our experimental observations (Figs. 1A and B) show the incapacity of T human lymphocytes to uptake histatin-5 labelled with FITC, but on the same time our results demonstrate that the histatin-5 toxic selectivity is not exerted on the mammalian mitochondria, indicating that mammalian mitochondria may be used to study the histatin-5 mediated effects at comparative level.

It is therefore interesting to outline that part at least of the mechanisms responsible for histatin-5 toxicity operating in mammalian mitochondria involves both inhibition of the respiratory activity and dissipating of the transmembrane potential $(\Delta \Psi)$, sharing similarities with the toxic mechanisms operating in $C$. albicans.

\section{Acknowledgments}

This study was supported in part by MIUR Grant "COFIN 2002" and CNR Grant "Agenzia 2000" assigned to R.P. 


\section{References}

[1] E.A. Azen, W. Leutenegger, E.H. Peters, Evolutionary and dietary aspects of salivary basic $(\mathrm{Pb})$ and post $\mathrm{Pb}(\mathrm{PPb})$ proteins in anthropod primates, Nature 273 (1978) 775-778.

[2] A.Y. Balekjian, R.W. Longton, Histones isolated from human parotid fluid, Biochem. Biophys. Res. Commun. 50 (1973) 676-682.

[3] F.G. Oppenheim, T. Xu, F.M. McMillian, S.M. Levitz, R.D. Diamond, G.D. Offner, R.F. Troxler, Histatins, a novel family of histidine-rich proteins in human parotid secretion. Isolation, characterization, primary structure, and fungistatic effects on Candida albicans, J. Biol. Chem. 263 (1988) 7472-7477.

[4] R.F. Troxler, G.D. Offner, T. Xu, J.C. Vanderspek, F.G. Oppenheim, Structural relationship between human salivary histatins, J. Dent. Res. 69 (1990) 2-6.

[5] D.I. Hay, Fractionation of human parotid salivary proteins and the isolation of an histidine-rich acidic peptide which shows high affinity for hydroxyapatite surfaces, Arch. Oral Biol. 20 (1975) $553-558$.

[6] T. Kato, N. Takahashi, H.K. Kuramitsu, Sequence analysis and characterization of the Porphyromonas gingivalis prtC gene, which expresses a novel collagenase activity, J. Bacteriol. 174 (1992) 3889-3895.

[7] M. Nishikata, T. Kanehira, H. Oh, H. Tani, M. Tazaki, Y. Kuboki, Salivary histatin as an inhibitor of a protease produced by the oral bacterium Bacteroides gingivalis, Biochem. Biophys. Res. Commun. 174 (1991) 625-630.

[8] F.G. Oppenheim, Y.C. Yang, R.D. Diamond, D. Hyslop, G.D. Offner, R.F. Troxler, The primary structure and functional characterization of the neutral histidine-rich polypeptide from human parotid secretion, J. Biol. Chem. 261 (1986) 1177-1182.

[9] K. Sugiyama, Y. Suzuki, H. Furuta, Isolation and characterization of histamine-releasing peptides from human parotid saliva, Life Sci. 37 (1985) 475-480.

[10] F.G. Oppenheim, G.D. Offner, R.F. Troxler, Amino acid sequence of a proline-rich phosphoglycoprotein from parotid secretion of the subhuman primate Macaca fascicularis, J. Biol. Chem. 260 (1985) 10671-10679.

[11] E.J. Helmerhorst, I.M. Reijnders, W. van 't Hof, E.C. Veerman, A.V. Nieuw Amerongen, A critical comparison of the hemolytic and fungicidal activities of cationic antimicrobial peptides, FEBS Lett. 449 (1999) 105-110.

[12] H. Situ, L.A. Bobek, In vitro assessment of antifungal therapeutic potential of salivary histatin-5, two variants of histatin-5, and salivary mucin (MUC7) domain 1, Antimicrob. Agents Chemother. 44 (2000) 1485-1493.

[13] R.P. Santarpia, M.I. Cho, J.J. Pollock, Parameters affecting the inhibition of Candida albicans GDH 2023 and GRI 2773 blastospore viability by purified synthetic salivary histidine-rich polypeptides, Oral. Microbiol. Immunol. 5 (1990) 226-232.

[14] J.J Pollock, L. Denepitiya, B.J. MacKay, V.J. Iacono, Fungistatic and fungicidal activity, Infect. Immun. 44 (1984) 702-707.

[15] S.E. Koshlukova, T.L. Lloyd, M.W. Araujo, M. Edgerton, Salivary histatin 5 induces non-lytic release of ATP from Candida albicans leading to cell death, J. Biol. Chem. 274 (1999) 1887218879.

[16] E.J. Helmerhorst, W. van't Hof, P. Breeuwer, E.C. Veerman, T. Abee, R.F. Troxler, A.V. Amerongen, F.G. Oppenheim, Characterization of histatin 5 with respect to amphipathicity, hydrophobicity, and effects on cell and mitochondrial membrane integrity excludes a candidacidal mechanism of pore formation, J. Biol. Chem. 276 (2001) 5643-5649.

[17] E.J. Helmerhorst, P. Breeuwer, W. van't Hof, E. WalgreenWeterings, L.C. Oomen, E.C. Veerman, A.V. Amerongen, T. Abee, The cellular target of histatin 5 on Candida albicans is the energized mitochondrion, J. Biol. Chem. 274 (1999) 7286-7291.
[18] C. Gyurko, U. Lendenmann, E.J. Helmerhorst, R.F. Troxler, F.G. Oppenheim, Killing of Candida albicans by histatin 5: cellular uptake and energy requirement, Antonie Van Leeuwenhoek 79 (2001) 297-309.

[19] E.J. Helmerhorst, R.F. Troxler, F.G. Oppenheim, The human salivary peptide histatin 5 exerts its antifungal activity through the formation of reactive oxygen species, Proc. Natl. Acad. Sci. USA 98 (2001) 14637-14642.

[20] S. Melino, S. Rufini, M. Sette, R. Morero, A. Grottesi, M. Paci, R. Petruzzelli, $\mathrm{Zn}(2+)$ ions selectively induce antimicrobial salivary peptide histatin-5 to fuse negatively charged vesicles. Identification and characterization of a zinc-binding motif present in the functional domain, Biochemistry 38 (1999) 9626-9633.

[21] J. Grogan, C.J. McKnight, R.F. Troxler, F.G. Oppenheim, Zinc and copper bind to unique sites of histatin 5, FEBS Lett. 491 (2001) 76-80.

[22] M. Edgerton, S.E. Koshlukova, T.E. Lo, B.G. Chrzan, R.M. Straubinger, P.A. Raj, Candidacidal activity of salivary histatins. Identification of a histatin 5-binding protein on Candida albicans, J. Biol. Chem. 273 (1998) 20438-20447.

[23] X.S. Li, M.S. Reddy, D. Baev, M. Edgerton, Candida albicans Ssa1/2 is the cell envelope binding protein from human salivary Histatin 5, J. Biol. Chem. 21 (2003) 28553-28561.

[24] D.R. Green, J.C. Reed, Mitochondria and apoptosis, Science 281 (1998) 1309-1312.

[25] J.C. Martinou, S. Desagher, B. Antonsson, Cytochrome $c$ release from mitochondria: all or nothing, Nat. Cell Biol. 2 (2000) E41E43.

[26] J.C. Goldstein, N.J. Waterhouse, P. Juin, G.I. Evan, D.R. Green, The coordinate release of cytochrome $c$ during apoptosis is rapid, complete and kinetically invariant, Nat. Cell Biol. 2 (2000) 156-162.

[27] S.C. Welburn, C. Dale, D. Ellis, R. Beecroft, T.W. Pearson, Apoptosis in procyclic Trypanosoma brucei rhodiense in vitro, Cell Death Differ. 3 (1996) 229-236.

[28] M.E. Moreira, H.A. Del Portillo, R.V. Milder, J.M. Balanco, M.A. Barcinski, Heat shock induction of apoptosis in promastigotes of the unicellular organism Leishmania (Leishmania) amazonensis, J. Cell. Physiol. 167 (1996) 305-313.

[29] A. Vardi, I. Berman-Frank, T. Rozenberg, O. Hadas, A. Kaplan, A. Levine, Programmed cell death of the dinoflagellate Peridinium gatunense is mediated by $\mathrm{CO}(2)$ limitation and oxidative stress, Curr. Biol. 9 (1999) 1061-1064.

[30] D. Arnoult, I. Tatischeff, J. Estaquier, M. Girard, F. Sureau, J.P. Tissier, A. Grodet, M. Dellinger, F. Traincard, A. Kahn, J.C. Ameisen, P.X. Petit, On the evolutionary conservation of the cell death pathway: mitochondrial release of an apoptosis-inducing factor during Dictyostelium discoideum cell death, Mol. Biol. Cell 12 (2001) 3016-3030.

[31] S. Desagher, J.C. Martinou, Mitochondria as the central control point of apoptosis, Trends Cell Biol. 10 (2000) 369-377.

[32] S.A. Susin, N. Larochette, M. Geuskens, G. Kroemer, Purification of mitochondria for apoptosis assays, Methods Enzymol. 322 (2000) 205-208.

[33] R.C. Scaduto Jr., L.W. Grotyohann, Measurement of mitochondrial membrane potential using fluorescent rhodamine derivatives, Biophys. J. 76 (1999) 469-477.

[34] S. Matsuyama, Q. Xu, J. Velours, J.C. Reed, The mitochondrial F0F1-ATPase proton pump is required for function of the proapoptotic protein Bax in yeast and mammalian cells, Mol. Cell 1 (1998) 327-336.

[35] M.O. Hengartner, The biochemistry of apoptosis, Nature 407 (2000) $770-776$

[36] H. Gusman, J. Grogan, H.M. Kagan, R.F. Troxler, F.G. Oppenheim, Salivary histatin 5 is a potent competitive inhibitor of the cysteine proteinase clostripain, FEBS Lett. 489 (2001) 97100 . 
[37] F. Madeo, E. Hrker, C. Maldener, S. Wissing, S. Lachelt, M. Herlan, K. Fe Lauber, S.J. Sigrist, S. Wesselborg, K.U. Frohlich, A caspase-related protease regulates apoptosis in yeast, Mol. Cell 9 (2002) 911-917.

[38] Y. Xu, I. Ambudkar, H. Yamagishi, W. Swaim, T.J. Walsh, B.C. O'Connell, Histatin 3-mediated killing of Candida albicans: effect of extracellular salt concentration on binding and internalisation, Antimicrob. Agents Chemother. 43 (1999) 2256-2262.
[39] D. Baev, X.S. Li, M. Edgerton, Genetically engineered human salivary histatin genes are functional in Candida albicans: development of a new system for studying histin candidacidal activity, Microbiology 147 (2001) 3323-3334.

[40] E. Perez-Paya, R.A. Houghten, S.E. Blondelle, The role of amphipathicity in the folding, self-association and biological activity of multiple subunit small proteins, J. Biol. Chem. 270 (1995) 1048-1056. 